\title{
Evolution of the Profile of a Polish Paralympian from Heidelberg to Tokyo Paralympic Games: A Study Protocol for a Prospective Longitudinal Study
}

Joanna Sobiecka

University School of Physical Education in Kraków

Anna Zwierzchowska ( $\square$ a.zwierzchowska@awf.katowice.pl)

Akademii Wychowania Fizycznego im. Jerzego Kukuczki w Katowicach

\section{Research Article}

Keywords: Paralympic athletes, socioeconomic status, determinants in disability sports, sporting achievements, Paralympic Games.

Posted Date: November 29th, 2021

DOI: https://doi.org/10.21203/rs.3.rs-1083481/v1

License: (c) (i) This work is licensed under a Creative Commons Attribution 4.0 International License.

Read Full License 


\section{Abstract}

The observation of sociodemographic characteristics is important for the characterization of Paralympic athletes and the identification of determinants of their athletic performance. The aim of this study is to present the changes that have occurred in the profile of the Polish Paralympian in the period from Heidelberg to Tokyo Paralympic Games based on basic demographic characteristics and selected social and sport-related features. The study included $n=646$ Polish Paralympic athletes, accounting for $96.6 \%$ of the population from the 1972-2021 Games. The research was conducted with the method of direct participant observation using a diagnostic survey. Analysis of the data showed that gender was not a differentiating factor among Polish Paralympic athletes, and the proportion of women was lower than men. Age, on the other hand, was a significant differentiating factor at $(p<0.05)$. Furthermore, a significant differentiation of athletes in terms of the structure of education was observed, with a tendency to a steady increase in its level in subsequent years (chi2 $=68.83 ; \mathrm{df}=8 ; \mathrm{p}<0.01)$. However, this did not have a significant effect on their professional fulfillment. The proportion of multiple participants of the Paralympic Games increased significantly (chi2 $=21.43 ; \mathrm{df}=8 ; \mathrm{p}<0.01$ ), while the proportion of athletes who won a Paralympic medal decreased (also significantly, chi2 $=59.11 ; d f=8 ; p<0.01$ ).

\section{Introduction}

When creating the profile of a Polish Paralympian, it should be mentioned that among the large group of people with disabilities involved in sports, only a few have been able to fully exploit their status as an athlete in other areas of life. Depending on the time when the disability occurred, they went through successive stages of rehabilitation and, by being physically active in recreational forms, they gradually started to engage in sport at a competitive level. In their quest to achieve the best possible athletic performance and to win competitions at an increasingly higher level, only a few have succeeded in achieving the highest sporting goal, which is being selected for the Paralympic team [1].

The first to go down in the history of Polish Paralympic sport were the participants of the 4th Summer Paralympics held in Heidelberg in 1972. Four years later, winter sports athletes also made their mark at the first Paralympic Winter Games in Örnsköldsvik. Since then, athletes from Poland have appeared at every Paralympic Games, except for the 2nd Paralympic Winter Games in Geilo in 1980. Therefore, over the course of 49 years (1972-2021), certain stages in the development of Polish Paralympic sport can be observed. In the beginning, this sport was identified with rehabilitation and recreation in rehabilitation centers and treatment facilities. Then, the Zrzeszenie Sportowe Spółdzielczości Pracy "Start" (Workers' Cooperative Sports Association "Start") and Polski Związek Sportu Niepełnosprawnych "Start" (Polish Sports Association for the Disabled "Start") were established, which resulted in specific changes in the structure and management of sport for the disabled. The establishment of the Polish Paralympic Committee (PKPar) in 1998, which in 1999 was incorporated into the International Paralympic Committee (IPC), was an impulse for the coordination and development of sport for the disabled, with the idea of combining Olympic and Paralympic professional sport [2]. 
Undoubtedly, this process, together with the organizational changes, was closely linked to the social and especially economic and political transformations taking place in Poland, with historical significance for the sporting activity of people with disabilities. Furthermore, there has been continuous development in successive periods of Paralympic Games, which has led to changes in the composition of Polish national teams selected for the Games. Consequently, the profile of the Polish Paralympian has also evolved, which could be seen in the transformation that has taken place within the basic sociocultural characteristics of the athletes.

The aim of this study is to present the changes that have occurred in the profile of the Polish Paralympic athlete in 1972-2021 based on basic demographic characteristics and selected social and sport-related features. Answers to the following research questions were sought to achieve the study aim:

1. Are age and gender differentiating factors in the evolution of a Polish Paralympian in the period from Heidelberg to Tokyo Paralympic games?

2. How has the socioeconomic status of Polish Paralympic athletes evolved from Heidelberg to Tokyo?

3. Has the multiplication of participation of Polish athletes in the Paralympic Games had a significant effect on the number of medals won?

\section{Material And Methods}

\section{Material}

The study included 646 Polish Paralympic athletes with visual and motor impairments (Fig. 1)who have competed at the 1972-2021 summer and winter Paralympic Games (from Heidelberg to Tokyo Games). Due to the nature of the research (questionnaire survey), athletes with intellectual disabilities were excluded. A prospective longitudinal study protocol was used, with 5 stages of completion. This method allowed for distinguishing five groups of examined Paralympians.

Figure 1. Characteristics of the Polish Paralympic athletes participating in the Games from Heidelberg (1972) to Tokyo (2021).

Stage 1: $\mathbf{8 8 \%}$ of all Polish Paralympic athletes competing during the indicated period of the Games representing Poland in 8 sports (5 summer and 3 winter sports) were examined.

Stage 2: $94 \%$ of all Polish Paralympic athletes competing during the indicated period of the Games representing Poland in 12 sports ( 9 summer and 3 winter sports) were examined.

Stage 3: $\mathbf{9 8 \%}$ of all Polish Paralympic athletes competing during the indicated period of the Games representing Poland in 16 sports (13 summer and 3 winter sports) were examined.

Stage 4: $99 \%$ of all Polish Paralympic athletes competing during the indicated period of the Games representing Poland in 18 sports (14 summer and 4 winter sports) were examined. 
Stage V: $100 \%$ of Polish Paralympic athletes competing in Tokyo in 12 sports were examined.

There were $n=646$ Paralympic athletes surveyed, accounting for $96.6 \%$ of all Polish athletes who have been selected for Paralympic teams between 1972 and 2021. At the same time, the fact of examining such a significant group $(95 \% \mathrm{Cl})$ allows for reaching the statistical significance of inference in qualitative-quantitative analyses at the level of $p<0.05$.

\section{Methods}

The examinations presented here were conducted according to the protocol for a prospective longitudinal study divided into five stages. The study of Paralympic athletes used the method of direct participant observation based on a diagnostic survey, conducted by the same person (the author of the study) at each stage. In further analysis, the ethnographic method was used, which is based on the observation and description of the behavior of a given society (group) in its natural environment, and a detailed description of reality.

A validated survey questionnaire developed by Joanna Sobiecka titled "Polish participants of the Paralympic Games" was used among the Paralympic athletes examined in Stages 1, 2, 3, 4 [1]. In Stage 5, research was conducted using a questionnaire survey developed by Jadwiga Kłodecka-Różalska, which was modified with the author's consent to suit the needs of disabled sports and entitled "A questionnaire for female and male athletes included in Paralympic training programs" [3].

For the purpose of this study, only the opinions of the respondents which concerned demographic (gender and age), social (marital status, educational, and occupational activity), and sporting (multiple participation in the Games and number of medals won) characteristics were extracted from the survey questionnaire.

At all stages, the examinations were performed based on the ethical principles formulated in the International Ethical Guidelines for Biomedical Research Involving Human Subjects, developed by the Council for International Organizations of Medical Sciences in collaboration with the World Health Organization, adopted in 1982 and amended in 1993 and 2002 (International ethical guidelines for biomedical research involving human subjects. Geneva: Council for International Organizations of Medical Sciences, 2002. (Accessed on 7 October 2021). All participants gave written consent to participate and they could withdraw from the research at any time.

Furthermore, prior to conducting the study among Paralympians at Stage 5, approval was obtained from the Bioethics Committee at the Regional Medical Chamber in Cracow (No. 218/KBL/OIL/2021 as of 16 July 2021).

\section{Statistical analysis}

Descriptive statistics and qualitative and quantitative analysis were used. Results for each stage of the research were presented. The arithmetic mean and standard deviation (SD) were calculated for the 
variable of Paralympian's age 0 . To test the significance of temporal changes for selected characteristics in each study area, chi2 and multiple Student's t-tests were used, with the level of statistical significance set at $p<0.05$.

\section{Results}

\section{Polish Paralympian: basic demographic determinants}

Age

Between 1972 and 2021, the age of the athletes varied statistically at $p<0.01$. Significantly the youngest Paralympians were the respondents competing for Paralympic medals between 1972 and 1988, while significantly the oldest were the athletes participating in the 2021 Games. The greatest age heterogeneity was observed between Paralympic athletes in 2000-2010 (Fig. 1).

Gender

Analysis of gender structure of Polish Paralympic athletes in individual groups of respondents each time revealed that the proportion of women was lower than that of men, and statistical analysis did not confirm gender differentiation. At the same time, a significant increase in the proportion of women has been observed since 2000 in relation to those competing in 1972-1988 and 1992-1998 (Fig. 2).

\section{Polish Paralympian: social determinants}

Marital status

A comparison of the Polish Paralympic teams from 1972 to 2018 showed that it included both unmarried (divorced and cohabiting) and married athletes. However, over the 49 years studied, unmarried Paralympians dominated, but their percentage did not show an upward trend. Exceptions were athletes participating in the 1992-1998 Games, with 52\% starting families (Fig. 3).

Educational activity

Analysis of the educational structure of the Polish Paralympic teams in 1972-2021 revealed that the athletes have graduated from schools at different levels, from primary to higher education. However, graduates of secondary schools (vocational and comprehensive schools) significantly dominated among the respondents. However, in the group of participants of the 1972-1988 Olympics, the greatest number of athletes had basic vocational or lower education, while in subsequent periods of the Games, their participation in the national teams showed a significant declining trend. A different situation was observed in the Polish team among athletes with university education. During the 49 years from Heidelberg to Tokyo Games, there has been a significant increase in the percentage of athletes who held a university degree (Fig. 4).

Economic activity 
Analysis of the changes in labor force participation observed among the respondents revealed the Paralympian community of the 1972-2021 Games included athletes who have been economically active, not in the labor force, unemployed, and school or university students. Furthermore, it was found that the Polish national teams have been significantly dominated by working Paralympians over the period studied. However, in subsequent periods of the Paralympic Games, a significant declining trend was found for the participation of economically active Paralympic athletes in the Polish national team. Therefore, a statistically significant increase in the percentage of unemployed athletes, those not in the labor force (especially in 2021), and participants being school or university students (especially in 20002010) was demonstrated (Fig. 5).

\section{Polish Paralympian: sport determinants}

Multiple participation in the Games

The observation showed that the structure of Paralympians in terms of multiple participation in successive Paralympic Games has changed significantly over the period of 1972-2021. The years 19721998 were significantly dominated by athletes who competed in the Paralympic Games only once, while since 2000, multiple Games participants have been most numerous (Fig. 6).

Medal achievements

Analysis of medal achievements in successive years of the Paralympic Games demonstrated that the percentage of athletes winning medals for Poland in the national teams has been significantly decreasing. During the 1972-1988 Games, only every fourth athlete did not stand on the Paralympic podium, while at the Tokyo Games (2021), the opposite was true, with every fourth Para athlete winning a medal (Fig. 7).

\section{Discussion}

The Polish comprehensive research presented in this study (concerning demographic, social, and sport characteristics) among the athletes selected for the Paralympic team over the 49 years of the Games from Heidelberg to Tokyo is unique. The research is longitudinal, conducted regularly, and covers $96.6 \%$ of all Paralympic athletes, from the first participation of the Polish team at the 4th Paralympic Summer Games in Heidelberg in 1972 to the present year, i.e. 16th Paralympic Summer Games in Tokyo in 2021. There are no similar longitudinal studies available in the literature. Therefore, it is difficult to compare the results obtained for other national Paralympic teams. Nevertheless, individual sociodemographic characteristics are in the area of interest of researchers primarily as independent variables that often determine athletic performance and prevalence of sports injuries or are used to identify disease risks among Paralympic athletes [4-8]. The sociodemographic characteristics that have been often analyzed in publications are used only to characterize the respondents in a given sport and refer to specific 
Paralympic Games or a Paralympic preparation period without taking into account temporal changes. Among such independent variables, it is important to point out age and gender, which were also analyzed in the present study taking into account the above-mentioned changes. Our results clearly indicated that age is a differentiating variable between Polish olympic athletes (1992-1998 $=24,2000-2010=24)$ and all Paralympic athletes $(1992-1998=31,2000-2010=28)$ [1]. This may have been caused by the conditions of becoming disabled, rehabilitation process, and taking up sports adapted to the person's functional and sensory capabilities [9]. Given the above, it is not surprising that the oldest athletes in Poland who have competed in the Games for the first time are: the athletes from London (2012) such as a 54-year-old table tennis player and a 53-year-old archer, and a sailor who, at the age of 56 years, started his Paralympic career in Rio de Janeiro (2016). It can be observed that in Paralympic sport, athletes are not limited by age, which is especially confirmed by Paralympians from Poland who competed at the Games between 2000 and 2010. This is because the greatest statistically significant age heterogeneity among Paralympic athletes occurred during this period. The youngest athlete to be selected for the Sydney Games (2000) was an 11-year-old table tennis player, and the oldest was an archer who, at the age of 61 , achieved a Beijing 2008 Paralympic nomination for the third time. Our results are consistent with the data presented in the study by Derman et al., where the authors showed that of $n=3657$ participants in the 2016 Summer Paralympic Games, as many as $n=1341$ were in the age group of $35-75$, and the largest groups were Paralympic athletes $(n=246)$ and table tennis players $(n=112)$ [5]. Furthermore, the least numerous group of these games ( $n=996)$ were participants aged 12 to 25 years. Similar quantitative analyses were undertaken by Derman et al. in terms of gender, although they concerned the prevalence of diseases during the 2016 Rio Paralympic Games [5]. Undoubtedly, these findings are consistent with those obtained in our study by confirming significantly more frequent participation of men $(n=2268)$ compared to women $(n=1389)$. In this context, it is important to note the introduction of gender parity by the International Paralympic Committee in 2008 , with a $30 \%$ threshold goal for female representation in athletes in each sport and national team [10]. Undoubtedly, this is a factor that has significantly changed the proportion of participation in competitive sports by women with disabilities over the past decade, and our study only confirms the upward trend in female participation.

In addition to demographic aspects, another issue in creating the image of a Polish Paralympian is his or her socio-economic status identified based on education and professional and family involvement. Interesting changes can be observed during the temporal analysis by marital status. It was demonstrated that the years of the Games 1972-1988 and 2000-2021 were dominated by unmarried athletes. However, when the study was repeated in 1999 to examine the group from the period of 1972-1988, it turned out that about $66 \%$ of the participants of the Games were already married [11]. The athletes emphasized that during their professional sports careers, they were focused primarily on combining their sporting duties with acquiring specific education, while they postponed (especially women) the decisions about starting families for the period after the end of their sporting careers [12]. This is the more so as since the preparation for the 2012 London Paralympic Games, finding a balance between personal life and sporting careers has been increasingly difficult, especially because the athletes performed 12 training 
sessions per week and the organizational structure of disability sport has evolved significantly due to socioeconomic changes in Poland [13-14].

An equally important problem in creating an evidence-based image of a Polish Paralympian is his or her education and economic activity. Not without significance in this case were the systemic conditions and reforms which occurred in Poland at the end of the 1990s, which, in retrospect, had an impact on the level of education of the respondents. The first group of Paralympic athletes from 1972-1988 was dominated by basic vocational education, similarly to the group from 1992-1996. This was a consequence of systemic solutions in education, as the education of people with disabilities was carried out within the special education system, limited to vocational education, followed by employment in disability cooperatives. In the following years, the introduction of a reform of the structure of primary and secondary education (in 1999) and the changes in the school system were of key importance for the process of educating athletes from Paralympic teams in 2000-2021. Since then, there has been a regular transition from education in the segregation education system (special schools) towards the integration and inclusive education in Poland and worldwide [15-16]. Athletes with disabilities felt not only satisfied with the inclusive education, but above all, appreciated that similar requirements and challenges were put before them. Consequently, they had the opportunity to fully develop and prepare themselves to function in the environment of able-bodied people, and, at a later stage, to continue their education at universities [17]. Furthermore, the possibility of receiving financial support in the form of scholarships irrespective of family income, such as university rector's scholarships for outstanding achievements in science or sport or Minister's scholarships for similar achievements were the factors encouraging Paralympic athletes to pursue education at all levels [1].

The qualitative analysis performed using the ethnographic method among Polish Paralympic athletes in individual periods of the Games over the years 1972-2021 shows subsequent changes in their profile taking into account economic activity. It was not surprising that in 1972-1988, the athletes from the Polish Paralympic team were more often economically active compared to other stages of the research. This fact is closely related to the organizational structure of Polish sport for people with disabilities that existed until the early 1990s. In that period, the sporting activity was concentrated mainly on the community of disabled employees of worker cooperatives for the disabled, with clubs and sections of various sports. Therefore, it can be concluded that with their employment in cooperatives, disabled people had the opportunity to practice sport [2]. Nowadays, in the era of inclusive policies and better systemic solutions in education, both in Poland and worldwide, Paralympic athletes, after ending their sports careers, can try to find their place in the sport sector as assistants or coaches, which is confirmed by preliminary studies conducted in the field of coaching and educational services [18].

The presented causal consistency of the results is consistent with few conclusions from the studies published by other authors. However, their explorations were conducted in countries with different legislative and systemic solutions [19]. Unfortunately, there are no studies in the available literature that are similar to the analysis presented here and consistent with the protocol of longitudinal prospective study to address the socioeconomic status of Paralympic athletes. Most often, the problems of the 
socioeconomic status of Paralympic athletes have been explored by researchers from a global perspective, by assessing their quality of life, sense of life satisfaction, or professional fulfillment after the end of their sport career [18, 20-21].

Athletic performance and medals won have been often considered an indicator of success. However, with the changes concerning the classification rules and an increasing number of national teams taking part in subsequent Games, it is becoming increasingly difficult for the athletes to win the coveted Paralympic medal. This is evidenced by the tendency in Polish sport for the proportion of athletes who have won Paralympic medals to fall gradually. This fact is confirmed by the new system of classifying athletes for particular sports and Paralympic events introduced in 1992 [22-23]. The reduction in sport classes has had an effect on raising the level of athletic performance, thus increasing the competition for Paralympic medals. An additional constraint was the advent of new eligibility rules for athletes to compete at the Paralympics. Since 1996, following the example of Olympic sport, national disability sport organizations have no longer decided on the sporting criteria that an athlete should meet in order to receive a Paralympic nomination. The ever-increasing athletic performance and popularity of many sports made it necessary for IPC to introduce qualifying tournaments for athletes wanting to participate in the Games. In addition to the results obtained at continental events, the rankings of athletes were also based on the results they obtained at major international competitions. Therefore, only the best athletes from a given continent could participate in the Games in a given sport and sport class.

The presentation of the sporting achievements of Polish Paralympians leads to the conclusion that other important benefits offered to medalists at the Games cannot be overlooked. In addition to sporting success, they have also the aspect of financial gratification. Similar to Olympic Games medalists, once their sporting career is over (when they turn 40 years of age and the statutory criteria are fulfilled), the Paralympians can apply for a cash benefit. Importantly, such benefits are awarded regardless of the financial situation to all athletes with disabilities who have won medals at the summer and winter Paralympic Games since 1972. Furthermore, since 2016, cash benefits have been paid to athletes for medals won by them at the Paralympic Games in exactly the same amount as to able-bodied Olympic athletes [2].

It is also worth noting that, as the years go by, the profile of the Polish Paralympian in terms of multiple participation in the Games is changing. Since the beginning of the 21 st century, the national team has been dominated by athletes who have competed in Paralympic Games more than once. This includes athletes who have competed 6 and 7 times and therefore remained within professional sports training for up to 24 years or more. Some of them did so to win a coveted Paralympic medal and, in the future, to be able to be awarded financial benefits. Others pursued successive personal records and became Olympic medalists at the same time. There are also champions who have won over a dozen medals, with one of them standing on the podium as many as 24 times.

\section{Strengths and weaknesses of the study}


We believe that a strength of the present research is its protocol (longitudinal study), but also the direct participation method and the fact that the survey was each time conducted by the same researcher, who is the author of this study. To justify this thesis, reference should be made to the emerging awareness among researchers of the importance of using protocols for a prospective longitudinal study. These protocols allow not only for observation of phenomena and identification of problems studied but they can be used to create remedial measures with a higher degree of certainty. Such attempts were made, among others, by the team of Fagher et al. [24] who published a research protocol dedicated to monitoring the health of athletes with disabilities.

The authors of the present study are aware of the weakness of this study, which lies in its limited conclusions since there have been no similar studies analyzing the problems over such a long time.

\section{Conclusion}

1. Gender is a factor that did not statistically significantly differentiate between Polish Paralympic athletes in the period of 1972-2021. At all stages of the survey analyzed in the study, the proportion of women was lower than men, with the expected upward trend. In contrast, age was a factor that significantly differentiated between the respondents, with the highest mean age ( $\overline{\mathrm{x}}=34.1$; SD 8.5) observed for the Tokyo 2021 Paralympic athletes.

2. Over the years from 1972 to 2021 , the Polish Paralympic team saw a significant differentiation in terms of the structure of education, with a tendency to a steady increase in its level in subsequent years. This, however, did not have a significant impact on their professional fulfillment, as a significant trend has been shown among Paralympic athletes for a regular increase in the group of unemployed and those not in the labor force.

3. From Heidelberg to Tokyo, the proportion of multiple participation in the Polish Paralympic team has significantly increased in successive Paralympic Games, while the proportion of athletes who won a Paralympic medal has significantly declined. Therefore, training experience in the Paralympic team did not translate into an established and high athletic performance.

\section{References}

1. Sobiecka, J. The image of a Polish Paralympian. (University of Physical Education, Krakow 2013).

2. Sobiecka, J. The process of integrating Polish sports communities. Med. Rehabil. 24, 35-41 (2020).

3. Sobiecka, J., Plinta, R., Drobniewicz, K., Kłodecka-Różalska, J. \& Cichoń, K. Conditions for preparations for the 2008 Beijing Paralympic Games in the opinion of the Polish national team. Biomed. Hum. Kinet. 4, 29-37 (2012).

4. Zwierzchowska, A., Rosołek, B., Celebańska, D., Gawlik, K. \& Wójcik, M. The Prevalence of Injuries and Traumas in Elite Goalball Players. Int. J. Environ Res. Public Health. 17, 2496. https://doi.org/10.3390/ijerph17072496 (2020). 
5. Derman, W. et al. Sport, sex and age increase risk of illness at the Rio 2016 Summer Paralympic Games: a prospective cohort study of 51198 athlete days. Br. J. Sports Med. 52, 17-23. https://doi.org/10.1136/bjsports-2017-097962 (2018).

6. Jooste, J. \& Kubayi, A. N. Perceived coach leadership style and psychological well-being among South African national male wheelchair basketball players. Disabil Health J. 11, 655-659. https://doi.org/10.1016/j.dhjo.2018.07.004 (2018).

7. Gawlik, K., Zwierzchowska, A. \& Rosołek, B. Evaluation of Lipid Metabolism and Nutritional Status in Male Goalball Players. J. Hum. Kinet. 48, 141-147. https://doi.org/10.1515/hukin-2015-0100 (2015).

8. Gawroński, W., Sobiecka, J. \& Malesza, J. Fit and healthy Paralympians - medical care guidelines for disabled athletes: a study of the injuries and illnesses incurred by the Polish Paralympic team in Beijing 2008 and London 2012. Br. J. Sports Med. 47, 844-849. https://doi.org/10.1136/bjsports2013-092298 (2013).

9. Sobiecka, J. Handicapped Persons' Sports as a Factor Consolidating the Effects of Treatment and Rehabilitation. Phys. Educ. Sport. 45, 53-63 (2001).

10. IPC (International Paralympic Committee). 2013 [cited 2021 Nov 3]; Available from: https://www.paralympic.org/news/ipc-addresses-need-more-female-paralympians.

11. Sobiecka, J. Rola sportu w procesie kompleksowej rehabilitacji polskich uczestników Igrzysk Paraolimpijskich. (University of Physical Education, Krakow 2000).

12. Sobiecka, J. Polskie paraolimpijki: sport i życie rodzinne. In Female athlete a woman of Success. Advantages and barriers of women's sport activities. (ed Kłodecka-Różalska, J.) 123-133 (PSSK, 2003).

13. Sobiecka, J. et al. Polish Paralympic sports in the opinion of athletes and coaches in retrospective studies. Int. J. Environ. Res. Public Health. 16, 4927. https://doi.org/10.3390/ijerph16244927 (2019).

14. Sobiecka, J. et al. Standards of Conditions During Preparations for the Summer Paralympic Games Between 2004 and 2012 Assessed by Polish Athletes. J Hum. Kinet. 48, 111-121. https://doi.org/10.1515/hukin-2015-0097 (2015).

15. Zwierzchowska, A. \& Szołtysek J. Educational suppport for university students with hearing impairments in public universities of the Silesian urban area (preliminary report: pilot study). CNS, 43, 5-13 (2019).

16. Block, M. E. \& Obrusnikova, I. Inclusion in physical education: a review of the literature from 19952005. Adapt. Phys. Act. Q. 24, 103-124. https://doi.org/10.1123/apaq.24.2.103 (2007).

17. Sobiecka, J. Education, socio-occupational structure and occupational work of Polish athletes participating in Paralympic Games Sydney 2000. Eukrasia. 5, 109-118 (2004).

18. Douglas, S., Falcão, W. R. \& Bloom, G. A. Career Development and Learning Pathways of Paralympic Coaches With a Disability. Adapt. Phys. Act. Q. 35, 93-110. https://doi.org/10.1123/apaq.2017-0010 (2018).

19. Haiachi, M. C., Cardoso, V. D., Reppold-Filho, A. R. \& Gaya, A. C. Reflections on the career of Brazilian Paralympic athletes. Cien Saude Colet. 21, 2999-3006. https://doi.org/10.1590/1413- 
812320152110.18512016 (2016).

20. Zwierzchowska, A., Żebrowska, A. \& Szkwara, M. Sports activities and satisfaction of living of men after cervical spinal cord injury. Pol. Ann. Med. 4, 205-208 (2017).

21. Samsoniene, L. et al. Neigaliuju sportininku gyvenimo kokybe ir kai kurie lygiu galimybiu aspektai [Quality of life of athletes with disability and some aspects of equal possibilities]. Medicina (Kaunas), 46, 211-218 (2010).

22. Tachibana, K. et al. Influence of Functional Classification on Skill Tests in Elite Female Wheelchair Basketball Athletes. Medicina. 55, 740. https://doi.org/10.3390/medicina55110740 (2019).

23. Ravensbergen, H. J., Mann, D. L. \& Kamper, S. J. Expert consensus statement to guide the evidencebased classification of Paralympic athletes with vision impairment: a Delphi study. Br. J. Sports Med. 50, 386-391. https://doi.org/10.1136/bjsports-2015-095434 (2016).

24. Fagher, K., Jacobsson, J., Timpka, T., Dahlström, Ö., \& Lexell, J. The Sports-Related Injuries and Illnesses in Paralympic Sport Study (SRIIPSS): a study protocol for a prospective longitudinal study. BMC Sports Sci Med Rehabil. 8, 28. https://doi.org/10.1186/s13102-016-0053-x (2016).

\section{Figures}

Polish Paralympic athletes from the 1972-2021 Games (N=646)

\begin{tabular}{|c|c|}
\hline $\begin{array}{c}\text { Stage 1 } \\
\text { 1988-1991 } \\
(\mathbf{n}=\mathbf{1 3 5}) \\
\overline{\mathrm{x}}_{\text {age: }} 26.0 \\
\text { (SD 6.4) } \\
\text { participants } \\
\text { of the Games in } \\
\text { 1972-1988 }\end{array}$ & $\begin{array}{c}\text { Stage 2 } \\
\text { 1998/1999 } \\
(\mathbf{n}=\mathbf{9 4 )} \\
\overline{\mathrm{x}}_{\text {age: }} 31.3 \\
\text { (SD 9.2) } \\
\text { participants of } \\
\text { the Games in } \\
\text { 1992-1998 }\end{array}$ \\
\hline
\end{tabular}

\begin{tabular}{|c|}
\hline Stage 3 \\
2010/2011 \\
$(\mathbf{n}=\mathbf{1 9 3})$ \\
$\overline{\mathrm{x}}_{\text {age: } 27.9}$ \\
(SD 9.4) \\
participants \\
of the Games in \\
2000-2010 \\
\hline
\end{tabular}

\begin{tabular}{|c|}
\hline Stage $\mathbf{4}$ \\
$2018 / 2019$ \\
$(\mathbf{n}=\mathbf{1 3 9})$ \\
$\overline{\mathrm{x}}_{\text {age: }} 31.5$ \\
(SD 9.1) \\
participants \\
of the Games in \\
2012-2018 \\
\hline
\end{tabular}

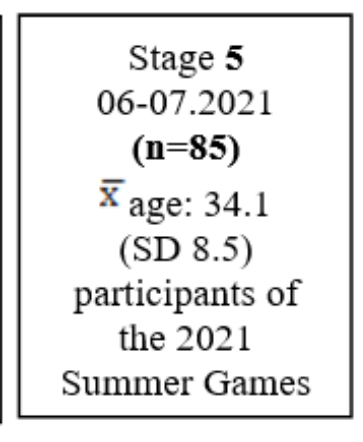

\section{Figure 1}

Characteristics of the Polish Paralympic athletes participating in the Games from Heidelberg (1972) to Tokyo (2021). 


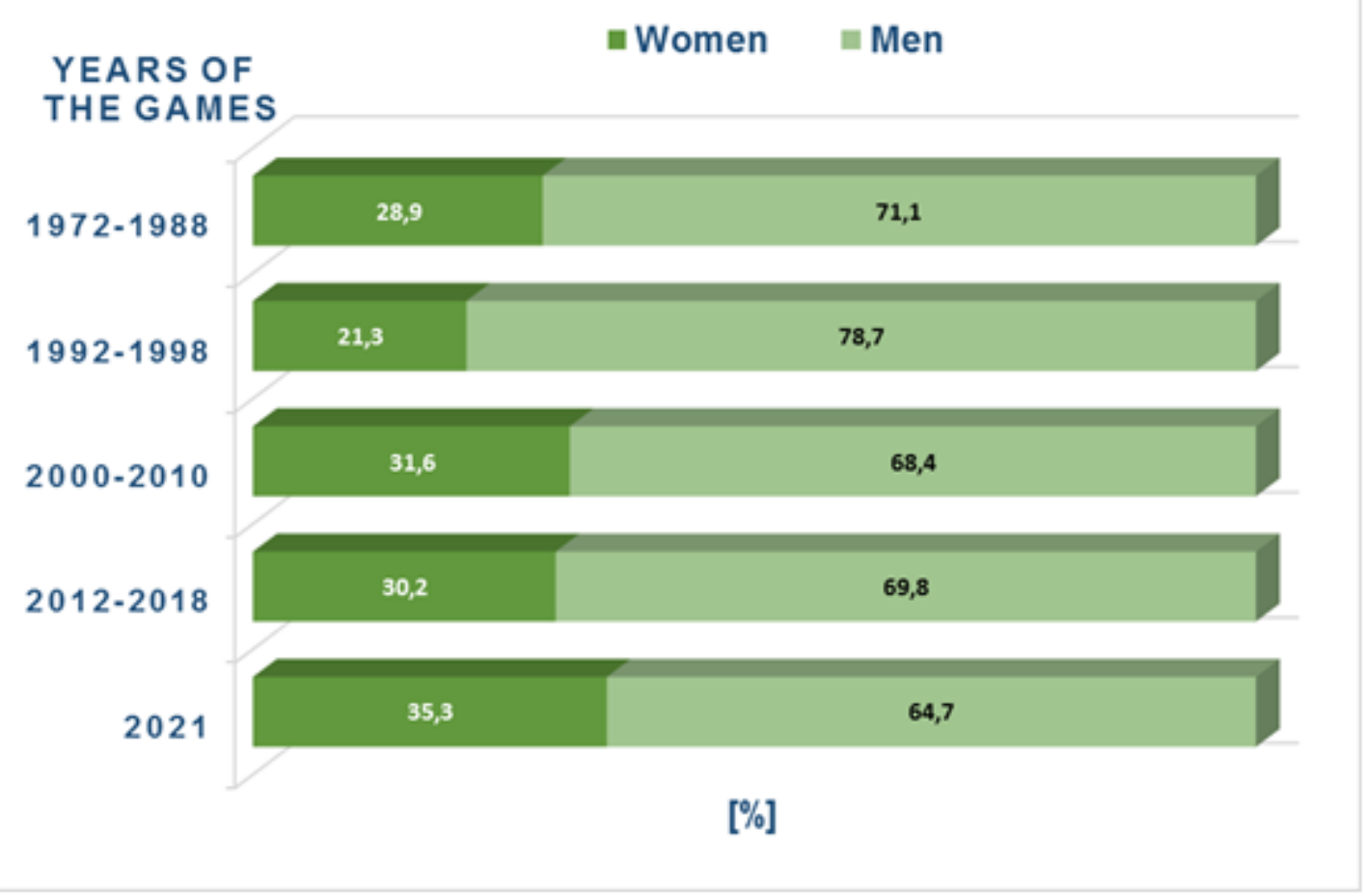

\section{Figure 2}

Structure of participants of the 1972-2021 Paralympic Games by gender $(p<0.01$; chi2 $=5.12 ; d f=8)$.

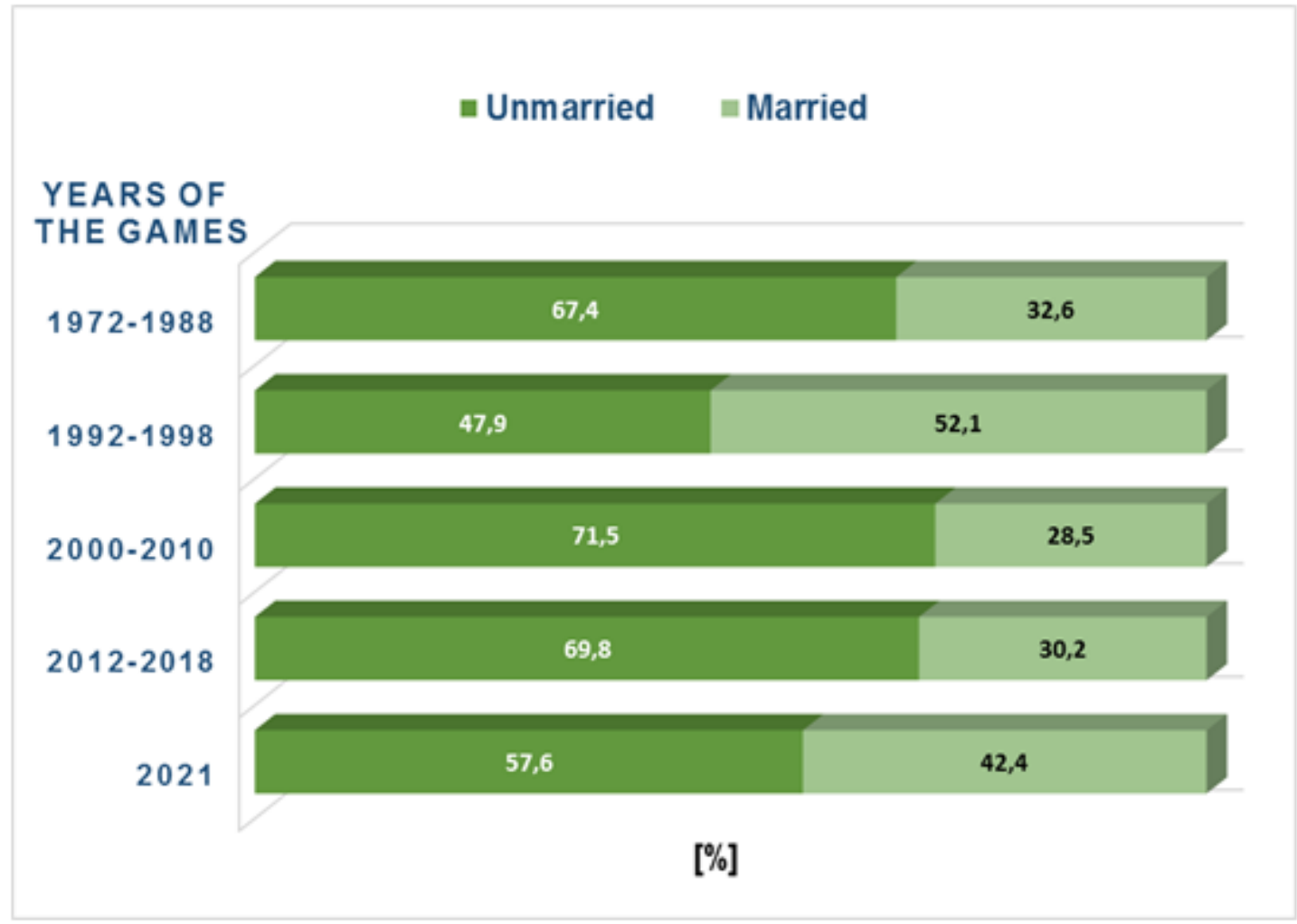

Figure 3 
Structure of participants of the 1972-2021 Paralympic Games by marital status $(p<0.01 ;$ chi2 = 16.96 ; df $=8)$.

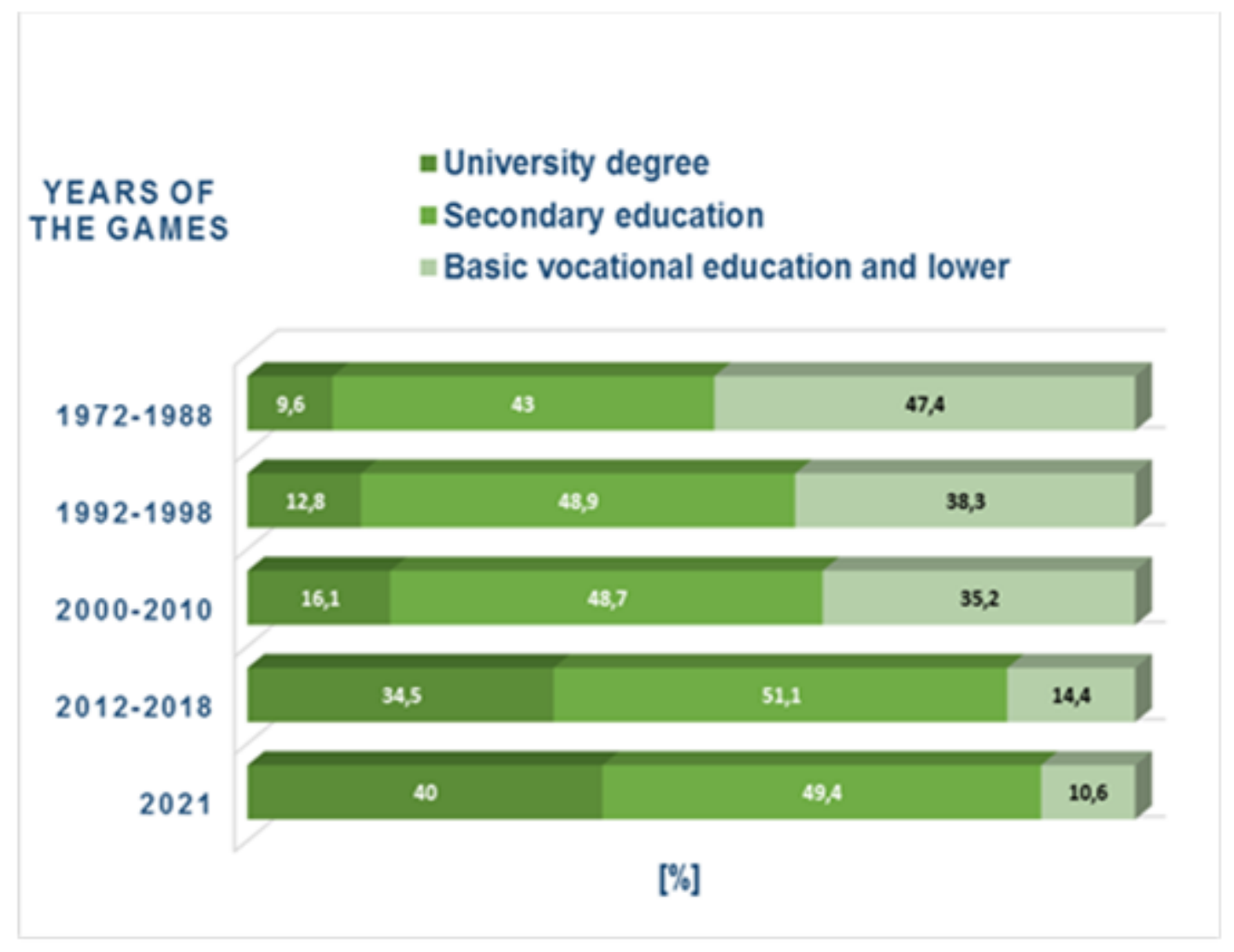

\section{Figure 4}

Structure of participants of the 1972-2021 Paralympic Games by education level $(p<0.01$; chi2 $=68.83$; df $=8)$. 


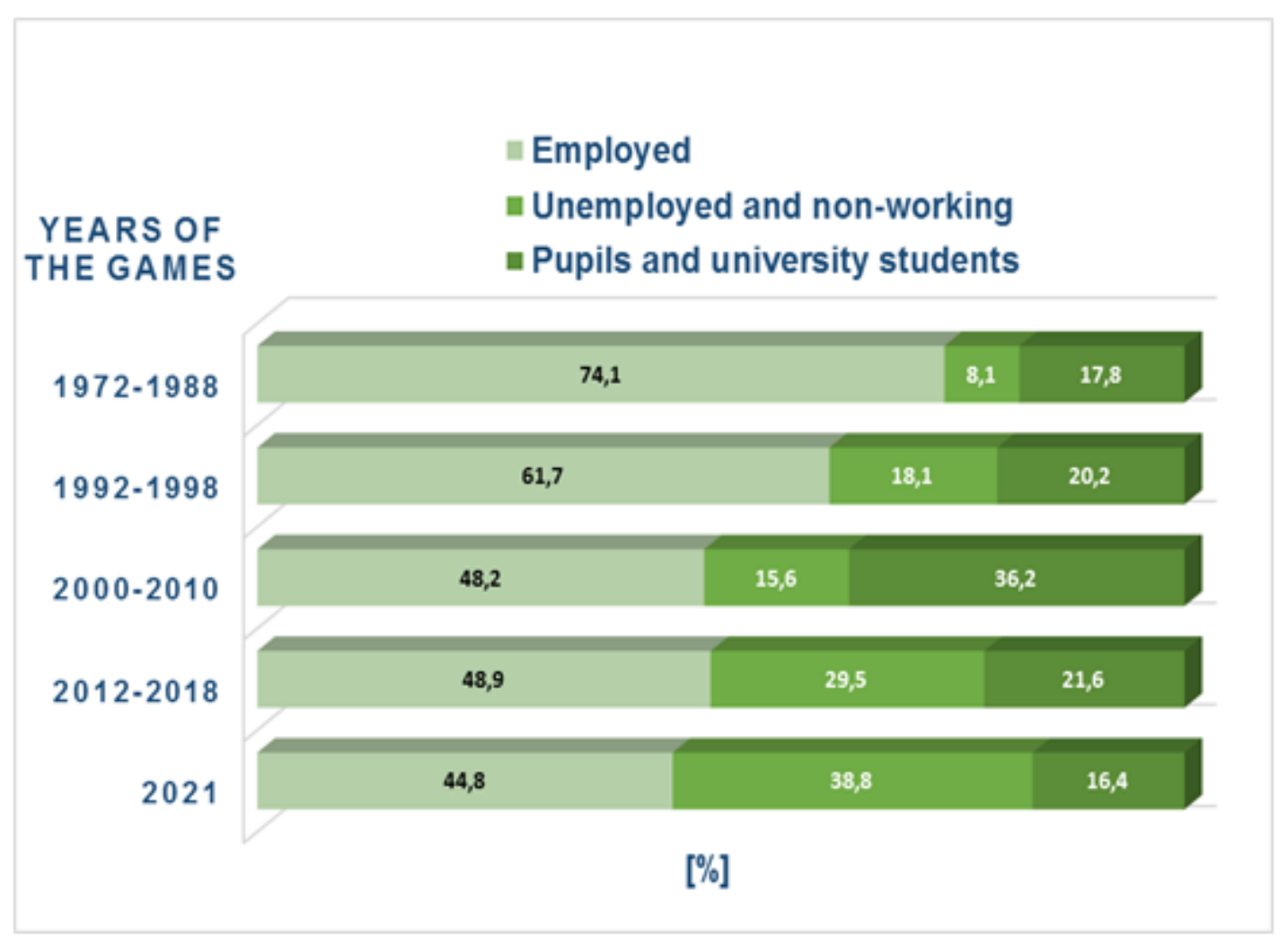

\section{Figure 5}

Structure of participants of the 1972-2021 Paralympic Games by economic activity $(p<0.01$; chi2 $=46.15$; $\mathrm{df}=8)$.

\section{घOnce $\quad$ Several times}

YEARS OF

THE GAMES

$1972-1988$

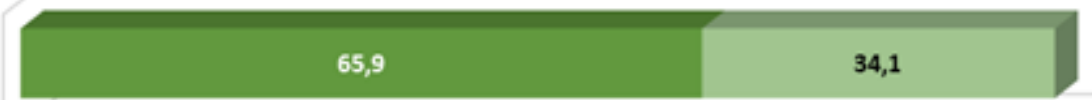

$1992-1998$

51,1

48,9

$2000-2010$

2012-2018

2021

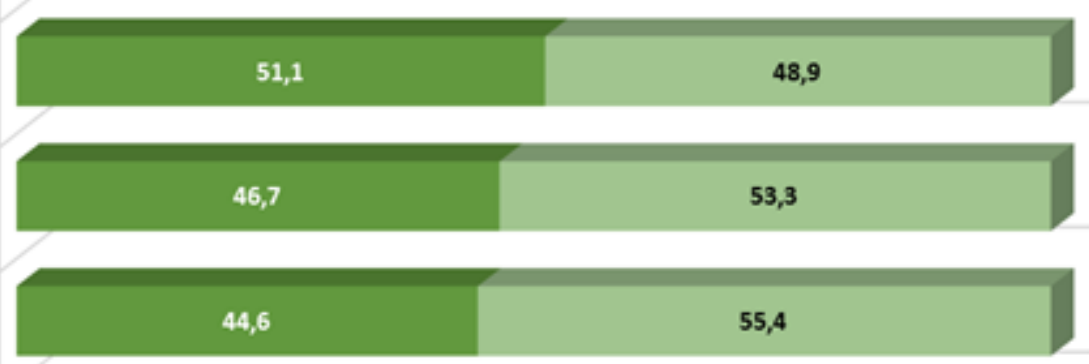

65,9

[\%] 
Figure 6

Structure of participants of the 1972-2021 Paralympic Games by participation in the Paralympic Games $(p<0.01 ;$ chi2 = 21.43; $\mathrm{df}=8)$.

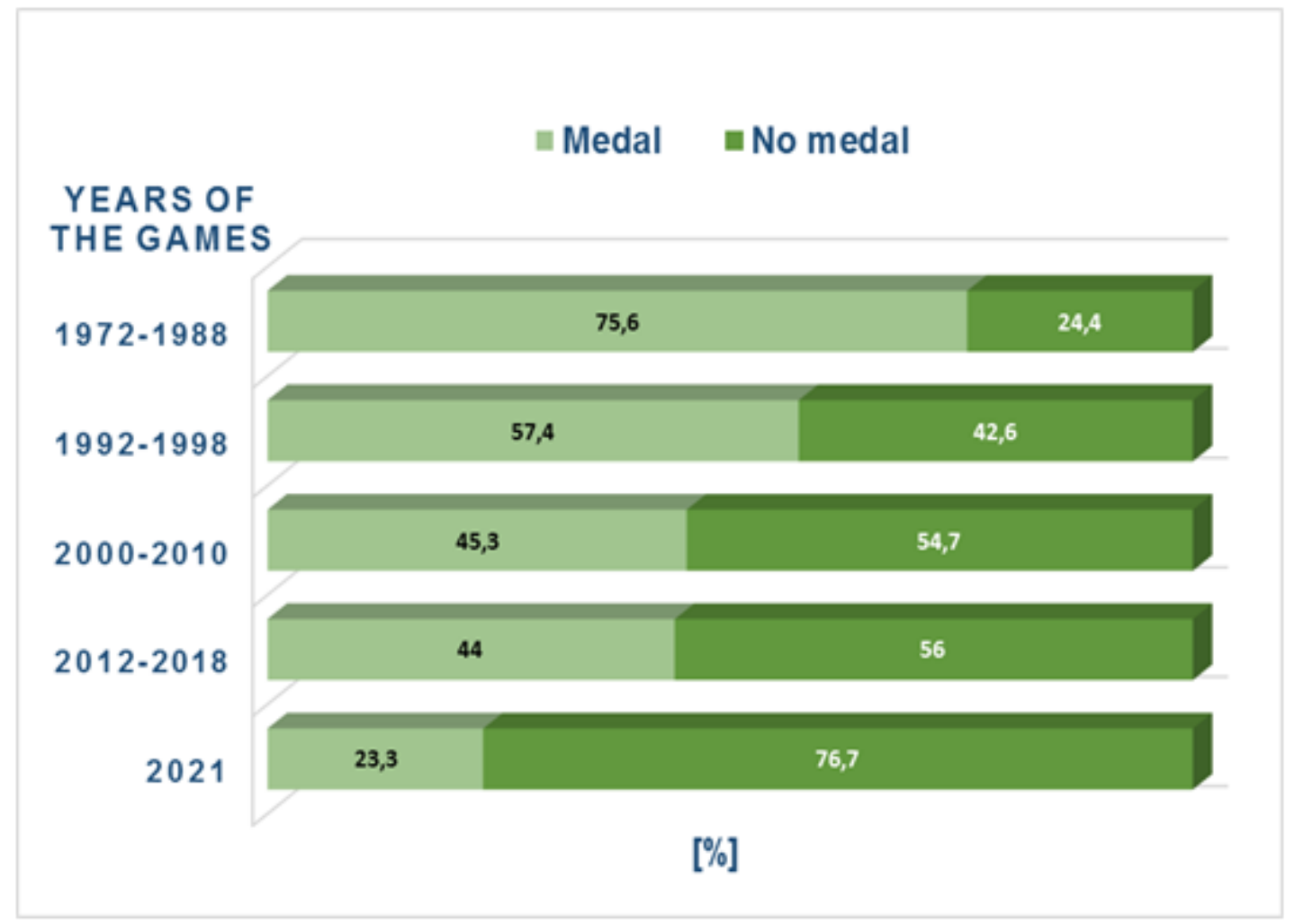

\section{Figure 7}

Structure of participants of the 1972-2021 Paralympic Games by medals won at the Summer and Winter Paralympic Games $(p<0.01 ;$ chi2 = 59.11; df = 8). 